\title{
PREVENTIVE ADMINISTRATION OF GS IMUNOSTIM AS A PROTECTION AGAINST ACUTE RESPIRATORY INFECTIONS
}

\author{
Jiří Stanek ${ }^{1}$, Vladimír Príkazský2 ${ }^{2}$ Jozef Rosina ${ }^{1}$, Alexander M. Čelko $^{1}$, Boris Št'astný ${ }^{3}$ \\ ${ }^{1}$ Charles University in Prague, $3^{\text {rd }}$ Medical Faculty, Prague, Czech Republic \\ ${ }^{2}$ National Institute of Public Health, Prague, Czech Republic \\ ${ }^{3}$ Canadian Medical Centre, Prague, Czech Republic
}

\begin{abstract}
SUMMARY
With respect to the fact that acute respiratory infections (hereafter ARI) are a world-wide serious social and economic problem, more and more attention is being paid to the development and application of oral bacterial immunomodulators.

The preventive effect of GS Imunostim has been evaluated during the respiratory season 2005. The study took place at 10 outpatient sites of general practitioners and lung specialists in Prague, Pilsen and Brno in the respiratory season from January to April 2005. The comparison with the ARI morbidity reports in the studied period revealed statistically significant morbidity reduction in the study participants compared to the ARI morbidity in the Czech population in the studied period from January to April 2005. The morbidity rate in the studied group was $7 \%$, whereas ARI morbidity $15.1 \%$ was reported in the general population. The morbidity in the study group was significantly lower that in the general population.
\end{abstract}

Key words: GS Imunostim, prevention, bacterial lysates

Address for correspondence: J. Stanek, Charles University in Prague, 3 $3^{\text {rd }}$ Medical Faculty, Ruská 87, 10042 Prague 10, Czech Republic. E-mail: jstanek@iol.cz

\section{INTRODUCTION}

A significant method of prevention against acute respiratory infections, especially against flu triggered by orthomyxoviruses, is vaccination (1). Vaccination is effective (the development of anti-flu vaccines is based on the currently circulating types of influenza virus stems), however, a considerable part of the population does not trust vaccination very much, including, paradoxically, some medical professionals. The vaccination rate in the Czech Republic has been low for a long time. For this reason, the vaccination level cannot prevent the epidemic spread of influenza, irrespectively to the fact that there are dozens of other so-called respiratory viruses, bacterial strains and other pathogenic agents in the population terrain (2).

Many pharmaceutical companies pay more and more attention to the development of oral bacterial immunomodulators which are used in the clinical practice more and more often. This is also due to the fact that part of these products is available to all doctors without any prescription limits. Some of them are available for the lay public as a food supplements. Bacterial immunomodulators are currently considered to be modern products with growing application; their positive effect depends on their application at the right time.

To the available immunomodulators belongs also GS Imunostim which has been approved as a food supplement in the Czech Republic. GS Imunostim comes in the form of pastilles to be dissolved in the mouth. They contain bacterial particles of some of the most common causative agents of upper respiratory tract infections. These so-called bacterial lysates can stimulate the immune system to create antibodies at the site of application (i.e. on the mucous of nasopharynx and oral cavity) and mobilize the immune system for the contingent encounter with bacterial or virus infections of the upper respiratory tract. This process resembles vaccination; for this reason GS Imunostim is sometimes referred to as "vaccination tablets". Similarly to other products in this group, GS Imunostim stimulates the defense mechanisms of the organism in a natural way.

\section{MATERIAL AND METHODS}

The aim of this study was to evaluate the efficacy of preventive administration of GS Imunostim in healthy subjects during the course of typical respiratory season.

103 healthy volunteers (46 males, 57 females), age range 8-76 years were offered and accepted participation in the study (Figure 1 shows their age and sex distribution). These subjects were recruited at random at 10 investigational sites (outpatient sites of general practitioners and lung specialists) covering the catchment area of the respective physicians in the Czech Republic from January to April 2005. Each subject had to confirm that he has not received influenza vaccination before the start-up of the respiratory season. The subjects have also committed not to get such vaccination during the study.

All study participants received GS Imunostim to be taken preventively according to the scheme delivered by the manufacturer.

Healthy subjects were invited to participate in the pilot research and received information about GS Imunostim and participant's 


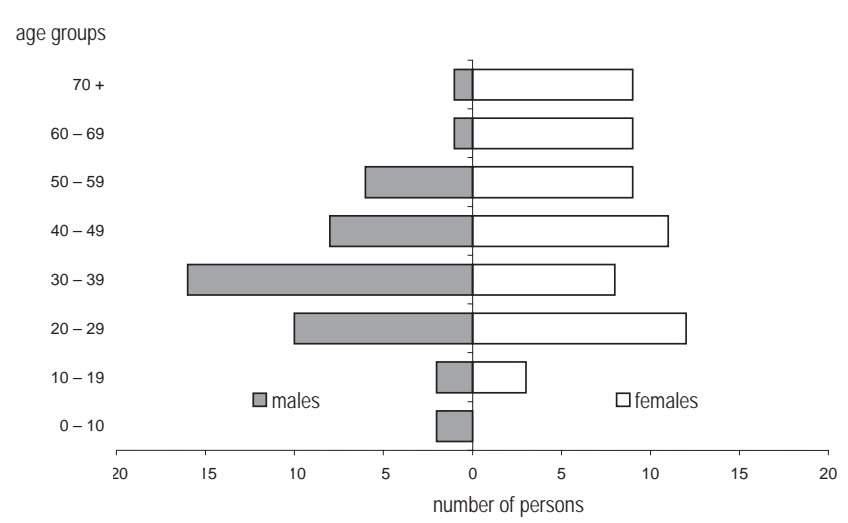

Fig. 1. Distribution of volunteers by age and sex.

diary from the doctor. The aim of the study was explained to the participants and they expressed their consent with the participation by their signature ensuring their compliance. Information about the course of the study (quality of life, respiratory morbidity) was documented in the physician's diary. After the healthy subjects have received GS Imunostim, their check-up visits were scheduled. The group of healthy volunteers was monitored for three months.

If acute respiratory disease occurred during the monitoring phase, the particular participant was withdrawn from the study.

The study was monitored by the investigational sites comparing the medical records source data and the data entered in the prepared case report forms. After verification, the study data were used for statistical evaluations.

Longitudinal observation of the ARI incidence during three months after the first use of the study drug and following the patient's health in case of an ARI occurrence, were also indicators for evaluating the effect of GS Imunostim. During the study, the participants were regularly asked about their health status by their attending doctor, either by the phone call or during the regular visits.

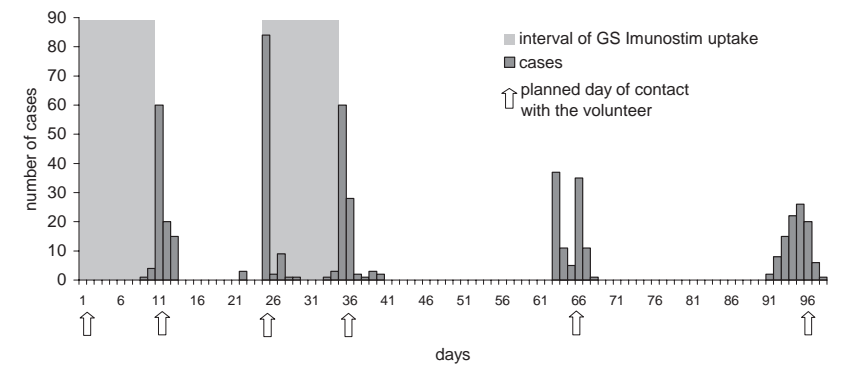

Arrow 1: start-up of 1 st dose uptake in the first dosage scheme period.

Arrow 2: termination of the last dose uptake, first interview for check of the subject (columns indicate the healthy volunteers numbers seen by the physician)

Arrow 3: start-up of 1st dose uptake in the second dosage scheme period. Second interview for check

Arrow 4: GS Imunostim uptake termination (follow-up contacts)

Arrow 5: interview with physician

Arrow 6: close-out

Fig. 2. Distribution of volunteers by day and contact since their recruitment.

\section{Biostatistical Evaluations}

Basic methods of epidemiological statistics, mainly $\chi^{2}$ and t-test ( $95 \%$ level) were used to assess the studied data of the healthy subjects taking GS Imunostim in the prophylactic regime.

For the analysis itself, a database was created and gradually completed and also within the CRF data in the EpiInfo system (CDC, Latest Version: Epi Info ${ }^{\mathrm{TM}}$ Version 3.3.2 release date: February 9, 2005). StandARI statistical methods were used for the evaluation.

\section{RESULTS}

During the preventive administration of GS Imunostim, there was no ARI occurrence in 96 (93\%) of the monitored healthy subjects. The comparison with the ARI morbidity reports in the studied period (Fig. 2) revealed a statistically significant morbidity reduction in the study participants compared to the ARI morbidity in the Czech population in the studied period from January to April 2005 (respiratory season 2004/2005). The morbidity rate in the studied group was $7 \%$, whereas $1,552,000$ ARI cases (15.1\%) were reported in the general population (3). Morbidity in the study group was 0.41 -times lower that in the common population $\left(\mathrm{OR}=0.41, \mathrm{KI} 95 \%=0.17-0.91, \chi^{2}=5.58\right.$, $\mathrm{p}=0.02$ ). The authors are fully aware of the fact that although the age distribution of the study sample is not fully compatible to age distribution of the general population, they consider such distribution be representative for the purpose of the study.

The study results suggest that GS Imunostim can be counted to products which are effective in the prevention of ARI. The study has shown that preventive administration of the study drug shortly before and during the ARI (influenza) epidemic can significantly strengthen the ability of the organism to defend itself.

Based on the study results, the authors recommend conducting controlled randomized studies, parts of which would focus on immunological effect and other important aspects of the preventative effect of GS Imunostim.

\section{DISCUSSION}

There has been new findings significantly contributing to our knowledge about the effect mechanism of immunomodulators (4). Bacterial stems (some revealed positive preventive effect on the development of the immune system already in new-born babies)

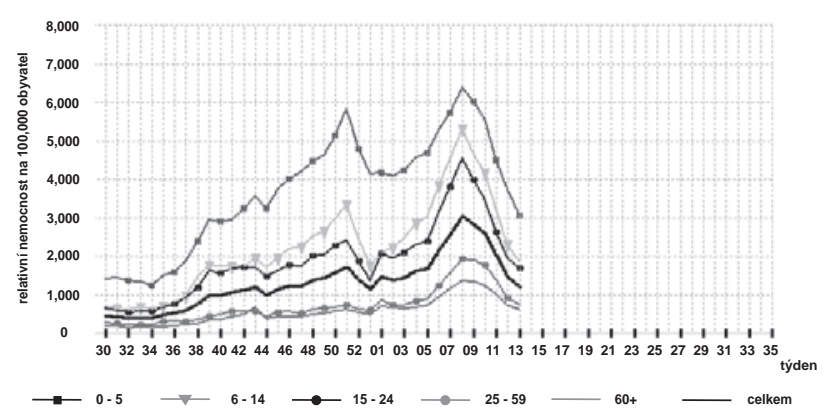

Fig. 3. Notification of acute respiratory infections in 2004/2005 season in the Czech Republic (SZU, www.szu.cz). 
which are used in different grades of elaboration and combinations available in commercial products are probably able to activate the immune system by means of pathogen-associated molecular patterns (PAMP).

Generally, the opinion prevails that bacterial immunomodulators elicit mainly a non-specific immune reaction by means of immunocompetent cells at the level of mucous membrane, and also submucous connective tissues (5). The last studies have confirmed that immunostimulators trigger the production of specific antibodies $(6,7)$. Drawing on the results of these studies, it can be expected that some commercially produced drugs administered orally can take effective mainly in a non-specific way first, but the activation of the immune system in a later stage (on order of weeks) can be followed by a specific immune response.

Some pharmacoeconomic studies have shown that correctly indicated prevention with bacterial immunomodulators lowers the health insurance expenditures.

This study has shown that GS Imunostim belongs to the group of products which are effective in strengthening the ability of the body to defend itself. Therefore, it is desirable to administer this product also preventively. The advantages of GS Imunostim are its easy application described in a comprehensive schedule, possible application without the necessity of prescription and its safety profile.

This study should be considered as pilot study only. The authors recommend that this study is the first step for planning and conduct of controlled randomized studies that would focus on the verification of the results of this study, including the immunological reaction after the application of GS Immunostim $(8,9,10,11)$.

There are also other factors contributing to health outcomes on respiratory morbidity, prevention and health. The vaccination effectiveness (etiology-related, specific interventions) has been studied/proved in several trials including the territory of the Czech Republic in recent years (12). It is also known that ARI morbidity and health outcomes are influenced by different factors, e.g. stress (13), life-style (14), air pollution (15) and others. The non-specific interventional approach including the administration of bacterial lysates will require further investigation.

\section{CONCLUSION}

ARI did not occur in $93 \%$ of the followed healthy subjects who took GS Immunostim preventatively (statistically relevant morbidity decrease in comparison to the ARI incidence in these volunteers in the past season and to the ARI morbidity in the Czech population in the followed period $(\mathrm{p}=0.02)$.

\section{REFERENCES}

1. Chlíbek R, Beran J, Špliňo M. Effectiveness of influenza vaccination in healthy adults - a fourfold decrease in influenza morbidity during one influenza season. Epidemiol Mikrobiol Imunol. 2002 Apr;51(2):47-51. (In Czech.)

2. Ensernik M. Epidemiology. Drugs, quarantine might stop a pandemic before it starts. Science. 2005 Aug 5;309(5736):870-1.

3. Havlíčková M, Otavová M, Kynčl J. Surveillance of acute respiratory infections in the Czech Republic in the season 2004-2005. Zprávy CEM. 2005;14:286-93. (In Czech.)

4. Bystron̆ J. Oral bacterial Immunomodulators and Evidence-Based Medicine. Alergie. 2003;5(4):284-290. (In Czech.)

5. Present options of immunomodulatory therapy in practice. Farmakoterap inform. 2005;(1):1-2. (In Czech.)

6. Tricarico D, Varricchio A, D'Ambrosio S, Ascione E, Motta G. Prevention of recurrent upper respiratory tract infections in a community of cloistered nuns using a new immunostimulating bacterial lysate. A randomized, double-blind clinical trial. Arzneimittelforschung. 2004;54(1):57-63. (In German.)

7. Rossi S, Tazza R. Efficacy and safety of a new immunostimulating bacterial lysate in the prophylaxis of acute lower respiratory tract infections. A randomised, open, controlled clinical trial. Arzneimittelforschung. 2004;54(1):50-6. (In German.)

8. Pozzi E, Serra C. Efficacy of Lantigen B in the prevention of bacterial respiratory infections. Monaldi Arch Chest Dis. 2004 Jan-Mar;61(1): 19-27.

9. Volgin AR, Demina IuV. Experience of using bacterial lysate IRS 19 for the prophylaxis of the diseases of respiratory organs in organized groups. Zh Mikrobiol Epidemiol Immunobiol. 2005 May-Jun;(3):82-4. (In Russian.)

10. Li J, Zheng JP, Yuan JP, Zeng GQ, Zhong NS, Lin CY. Protective effect of a bacterial extract against acute exacerbation in patients with chronic bronchitis accompanied by chronic obstructive pulmonary disease. Chin Med J. 2004 Jun;117(6):828-34.

11. Ekberg-Jansson A, Larsson S, Lofdhal CG. Preventing exacerbations of chronic bronchitis and COPD. BMJ. 2001 May 26;322(7297):1259-61.

12. Beran J, Moravík J. Effectiveness of vaccination against influenza in SkodaAuto Company employees during the influenza season 2000-2001. Cent Eur J Public Health. 2003;11(4):209-12.

13. Verma BK, Thakur DK. Effect of stressful environmental factors upon neonatal immune system. Cent Eur J Public Health. 1995;3(1):25-9.

14. Jedrychowski W, Kautery U, Flak E, Mroz E, Bianchi I. Cohort study on low physical activity level and recurrent acute respiratory infections in schoolchildren. Cent Eur J Public Health. 2001;9(3):126-9.

15. Pinter A, Rudnai P, Sarkany E, Goczan M, Paldy A. Air pollution and childrens, respiratory morbidity in the Tata area, Hungary. Cent Eur J Public Health. 1996;4 Suppl:17-20. 